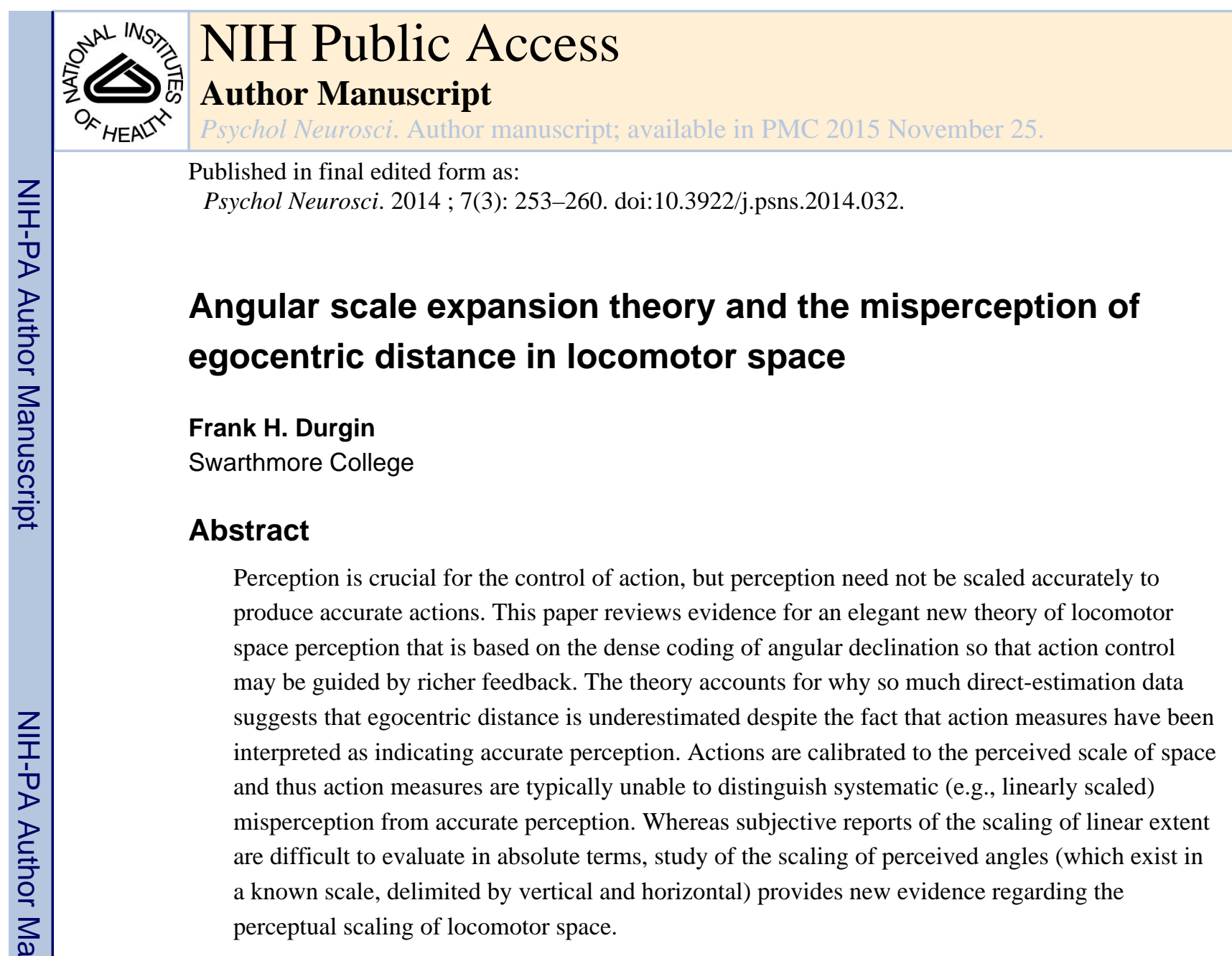

\title{
Keywords
}

Space perception; psychophysics; distance estimation

Do things in locomotor space seem closer than they are? Proposals about the nature of perceived egocentric distance have a long history, with many different kinds of experimental tasks producing different interpretations ranging from the idea that visual space perception is quite accurately scaled to the idea that it can't even be expressed in Euclidean terms.

Recently a functional account of distance underestimation has been proposed in conjunction with a more general treatment of the perception of locomotor space (Durgin \& Li, 2011a; Li \& Durgin, 2010, 2012). This new account integrates several kinds of evidence including direct numeric reports of perceptual experience, perceptual matching tasks and action measures, such as walking and pointing while walking. This new account proposes that the underestimation of space is a functional consequence of an efficient coding scheme concerned with the precise representation of angular variables that are useful for the control of action.

This paper provides a review of this theory in four sections. In the first section matching and estimation evidence is reviewed that suggests that egocentric distances along the ground

Frank H. Durgin, Department of Psychology, Swarthmore College, 500 College Avenue, Swarthmore, Pennsylvania 19081 USA. fdurgin1@ swarthmore.edu. 
seem shorter than they are whereas action measures suggest accurate egocentric distance perception. In this section it is argued that because there is no natural scale for distance that allows us to measure subjective experience directly, the existing evidence only establishes that the three directions (horizontal distance in depth along the ground plane, horizontal frontal extents on the ground plane, and vertical extents protruding out of the ground plane) seem to be perceived on different scales (no matter which type of measure is used). In the second section, evidence concerning errors in perceived angular direction is used to argue that we can indeed conclude that the geometry of space is distorted in specific ways given that angular scales ranging from horizontal to vertical provide a basis for mapping subjective experience. A third section explains why systematic perceptual biases in egocentric distance perception cannot be evident in action measures. Finally, the fourth section presents a discussion of the possible functional utility of the sort of distortion observed in angular variables. In brief, the argument will be that denser coding of directions near to straight ahead may underlie the perceptual biases observed. The denser coding provides more useful information (i.e., more sensitive perceptual feedback) for guiding action.

\section{Do things seem closer than they are?}

When asked to estimate distance using standard units like feet or meters, people tend to underestimate (Foley, Ribeiro-Filho \& Da Silva 2004; Kelly, Loomis \& Beall, 2004). The interpretation of these kinds of observations as suggesting the things seem closer than they are has sometimes been challenged on the grounds that underestimation may simply reflect a failure of verbal calibration. Indeed, success of verbal calibration for far distances has been demonstrated in athletes based on their awareness of standard field extents (Durgin, Leonard-Solis, Masters, Schmelz \& Li, 2012), but why is underestimation the norm? The measurement of perceptual experience, being inherently dependent on either verbal report or other behaviors, is no trivial task, and there have been conflicts over how best to quantify perceptual experience.

Gilinsky (1951) argued that perceived distance was hyperbolic. She found that ground extents needed to be larger and larger as they got farther away to appear equal. Her data implied that a hyperbolic function with an asymptote of about $28 \mathrm{~m}$ described egocentric distance perception. Although this pattern has been replicated using the same methods (Ooi $\& \mathrm{He}, 2007)$, it is not widely regarded as a definitive way to evaluate perceived egocentric distance. For one thing, Gilinsky's constant appears to depend on observer eye-height (Loomis \& Philbeck, 1999; Ooi \& He, 2007). Moreover, when asked to indicate the bisection point for very large egocentric distances, Gilinsky's theory implies people should set the bisection point much too close, but Purdy and Gibson (1955) reported that distance bisection in locomotor space was impressively accurate. Nonetheless, one aspect of Gilinsky's theory that is worth emphasizing is that it provides a model of how a physical dimension which is potentially unbounded (egocentric distance, construed abstractly) could be represented by a finite coding scheme in the brain.

Loomis, Da Silva, Fujita and Fukushima (1992) argued that the evaluation of exocentric distances showed compression that was not evident in the evaluation of egocentric distances. That is, when asked to compare frontal intervals and exocentric intervals in depth, the 
exocentric depth intervals appeared compressed, and had to be much larger than the frontal intervals to appear equal. But when asked to walk blindfolded to previewed targets, participants were unbiased in their walking for distances of up to $20 \mathrm{~m}$ away. Based on the linearity of the walking responses, the data of Loomis et al. help to reject a hyperbolic model of egocentric distance perception, and several studies suggest that the biased evaluation of exocentric ground extents in depth (such as studied by Gilinsky, 1951) may be better understood in terms of the misperception of shape via optical slant (Li \& Durgin, 2010, 2012, 2013; Loomis \& Philbeck, 1999; Loomis, Philbeck \& Zahorik, 2002).

Studies of distance perception that have fit power functions to egocentric distance estimates typically find an exponent very near to 1.0 (e.g., Da Silva, 1985; Teghtsoonian \&

Teghtsoonian, 1970). This suggests that the perception of distance is linear. But the question of whether distance perception is accurate or approximates linear compression is not easy to address. Loomis and Philbeck (2008) have argued that pointing remains accurate, but that verbal estimates of distance to a target made before and after walking obliquely past the target are inconsistent with Euclidean geometry of triangulation, as shown in Figure 1A.

However, the analysis of Loomis and Philbeck (2008) depends on the assumption that the walker has an accurate perception of the distance walked. The discrepancy between the verbal estimates and the walking responses could be interpreted another way. That is, on the one hand, the discrepancy between walking and estimating may signal that people perceived the distance accurately, but are poorly calibrated in their verbal estimates of distance. On the other hand, it might be that people really do underperceive the visual distance, and therefore also underperceive the distance of their walking as illustrated in Figure 1B.

Walking performance is calibrated by walking around in the perceived world, it would seem quite reasonable that people who perceive a visual distance of $10 \mathrm{~m}$ as $7 \mathrm{~m}$ would also perceive walking $10 \mathrm{~m}$ as walking $7 \mathrm{~m}$. There is nothing in the motor experience of walked distance to calibrate it except perceptual experience. That is, internal to the motor system, the units of walked distance might be expressed in terms of steps taken, normalized by the frequency of steps, which is correlated, for each walker, with step length (Durgin, Akagi, Gallistel \& Haiken, 2008; Durgin, Reed \& Tigue, 2007). If the units of motor control are not visual units, they must nonetheless be calibrated to visual units during everyday walking in order for predictive action to be successful. Thus, it is easy to imagine that when people walk $10 \mathrm{~m}$, they experience the distance travelled as only $7 \mathrm{~m}$ of visual units of distance. Indeed, when asked, verbally, to walk "7 m", without visual feedback, people walk out $10 \mathrm{~m}$ (Riemer, Hölzl \& Kleinböhl, 2014). This means that the perceptual experience of participants who appear to be failing at triangulation (Figure 1A) is actually consistent with triangulation if we simply replace the actual distance walked by the perceived distance walked, as represented in Figure 1B.

If verbal underestimation were the only source of evidence available, it is not obvious that scientists should find the above analysis compelling. But other methods of evaluating perceived egocentric distance also suggest that egocentric distance is compressed. For example, if one adapts the exocentric aspect ratio task used by Loomis et al. (1992), but with one leg as an egocentric distance and the other leg as an exocentric frontal extent, perceptual 
matching makes clear that the egocentric distance must be made greater than the frontal extent to appear equal to it (Li, Phillips \& Durgin, 2011). Whether asked to adjust their egocentric distance in order to match a frontal interval or asked to adjust the frontal interval to match their egocentric distance from it, participants reliably create a configuration in which the egocentric distance is much larger than the frontal extent. Similarly, when asked to match their egocentric distance to a vertical frontal extent, they set themselves much too far away (Higashiyama, 1996; Higashiyama \& Ueyama, 1988; Li et al., 2011; see Figure 3, below). The magnitude of the error with vertical extents is larger than the error with horizontal frontal extents, which is consistent with the observation that the VerticalHorizontal illusion is quite large for large-scale objects (Chapanis \& Mankin, 1967; Yang, Dixon \& Proffitt, 1999). What seems to be clear from these observations is that egocentric distances are compressed perceptually compared to both horizontal frontal extents and to vertical frontal extents. Moreover, when asked to walk out the distance of a frontal interval, blind walking measures overestimate the distance, consistent with the calibration idea above.

Of course, it could still be the case that both vertical and horizontal extents are actually exaggerated in perception, and that the egocentric extents are the only ones represented accurately. That is, even if we are convinced that the scaling of the linear dimensions of width, height and depth differs, how are we to determine which one is "correct"?

Magnitude estimation might underestimate egocentric distance simply because most people are more familiar with units of height than of egocentric distance. For example, in a study of verbal calibration it was recently reported that estimates of height were fairly accurate for poles that were four or six times the height of a person. The strategy reported by most participants was to estimate the pole relative to a person's height (Durgin et al., 2012). The most common extents that people may know in standard units are their own height. Given that height and depth seem to be differently scaled in perception, it could easily be that people are reporting egocentric distances in terms of the verbal height scale that they are most familiar with, and thus that verbal underestimation of ground extents is a result of the prevalent calibration of verbal reports of standard units to vertical extents (the heights of persons). In other words, even though there is consistent underestimation of perceived distance in verbal units, it is fairly easy to see how this may simply be a consequence of the differential scaling of height and distance. Thus, we seem to be able to draw conclusions about relative scaling (using both perceptual matching tasks and estimation tasks), and similar conclusions are even supported by walking actions (Li et al., 2013); but none of these data provide a firm basis for determining the absolute scaling of egocentric extents.

\section{Systematic bias in perceived gaze declination is consistent with egocentric distance underestimation}

Whereas there seems to be a clear "unit" problem for measures of linear extent (what do people mean by a "foot" or a "meter"?), the situation is somewhat different for angular measures. The scale for distance is bounded only at one end (zero), so the unit scaling of distance is inherently ambiguous, but the doubly-bounded range of angles between horizontal and vertical means that angular scales can be representationally unambiguously. If the angular distance between vertical and horizontal is specified as $90^{\circ}$, then it is clear 
where $45^{\circ}$ is, $30^{\circ}, 15^{\circ}$, etc. This unambiguous unit scaling is useful for evaluating the accuracy of space perception: In fact estimates of some angular variables relevant to the perception of locomotor space are systematically biased (Durgin \& Li, 2011a; Li \& Durgin, 2009).

In a study of the perception of downhill slant, $\mathrm{Li}$ and Durgin (2009) discovered that people show large errors in their proprioception of head tilt (fore and aft) and in the perceived direction of their gaze relative to horizontal. This contributes to the overestimation of downhill slant, but it is also relevant to the perception of visual distance because the angle of gaze declination below the horizontal ( $\gamma$, see Figure 2$)$ is a powerful distance cue (e.g., Messing \& Durgin, 2005; Ooi, Wu \& He, 2001; Wallach \& O'Leary, 1982), and Durgin and $\mathrm{Li}$ (2011a) pointed out that the errors in perceived gaze declination were consistent with the underestimation of distance that is commonly reported, as shown in Figure 2. Durgin and Li provided several assessments of perceived gaze declination, all of which indicated a perceptual gain of about 1.5 , such that participants judged a declination of $20^{\circ}$, for example, to be $30^{\circ}$.

These errors in angular perception are not simply verbal calibration errors. When asked to estimate the slants of surfaces (3D orientation) or the tilts of lines (2D orientation), people show systematic biases in their estimates, but there are several types of evidence showing that these biases are not verbal biases. First, the biases are different for judgments of 3D orientation and of 2D orientation (Durgin \& Li, 2012). More importantly, the biases are spatial rather than numeric: If asked to estimate the orientation of a line relative to vertical, numeric estimates will consistently underestimate the orientation in degrees. If asked to estimate the orientation of a line relative to horizontal, numeric estimates will consistently overestimate the orientation in degrees. Both of these responses are consistent with the spatial overestimation of orientation relative to horizontal. This same general pattern is true for surface orientation. In general, the use of numeric estimates of angles seems to be wellbehaved for measuring perceived spatial biases (Durgin \& Li, 2011b; Durgin, Li \& Hajnal, 2010). Moreover, if participants are asked to indicate whether a slanted surface (or a tilted line) is closer to vertical or to horizontal in order to estimate the perceived bisection point, the data demonstrate a pattern just like the numeric estimate of $45^{\circ}$. That is, for $3 \mathrm{D}$ surface slant, the bisection point is about $34^{\circ}$ from horizontal (Durgin et al., 2010). For 2D line orientation, the apparent bisection point is about $37^{\circ}$ from horizontal (Durgin \& Li, 2011b).

Durgin and Li (2011a) used three methods to assess bias in the perceived direction of gaze. One method (also used by Li \& Durgin, 2009) was to have participants explicitly estimate the angular direction (relative to horizontal) to real or virtual objects. Durgin and Li (2009) had people estimate the direction of their gaze when looking at specific objects from second story windows. Durgin and Li (2011a) conducted a more extensive experiment using golf balls placed at different locations on a slanted field (the slant of the field was intended to discourage people from trying to use ground distance to deduce the angle). Durgin and $\mathrm{Li}$ also had participants make similar judgments for balls presented in a virtual environment with only a ground plane (and horizon) visible. In each case, estimates of gaze declination in the tested range $\left(0-50^{\circ}\right.$ relative to horizontal) were best fit by functions with a slope of 1.5. 
A second, more indirect, method for estimating perceived gaze direction (or angular declination) is to have participants make geographical slant judgments when looking at surfaces presented along different gaze declinations/elevations. By evaluating the function relating optical slant to geographical slant, one can estimate the implied perceived gaze direction required to minimize signed error in this function across different gaze directions (for details, see Li \& Durgin, 2009; Durgin \& Li, 2011a). In the extreme, estimation of geographical slant for surfaces that are viewed with direction of gaze nearly parallel to the judged surface can be interpreted as estimates of gaze direction. The results of these methods agree with the direct verbal report of perceived gaze declination (Durgin \& $\mathrm{Li}$, 2011a).

One non-verbal method of assessing perceived direction of gaze is to have participants adjust the location of a ball until it appears to be in a direction that is halfway between straight-ahead and straight down. Assessments of this implicit perceived $45^{\circ}$ point, show that it is approximately $30^{\circ}$ below horizontal, again implying an angular perceptual gain of 1.5 relative to horizontal (Durgin \& $\mathrm{Li}, 2011 \mathrm{a}$ ). A second non-verbal method of assessing perceived gaze declination is simply to compare perceived egocentric distance with perceived height, as shown in Figure 3. That is, when participants are asked to set themselves the same distance from a pole as the pole is high (Higashiyama \& Ueyama, 1988; Li, Phillips, \& Durgin, 2011), the perceived equidistance point corresponds nearly perfectly to the position predicted if the angular declinations to the top and bottom of the pole are assumed to be misperceived with a gain of 1.5, as shown in the right panel of Figure 3.

Thus, a variety of explicit and implicit measures of perceived angular declination including judgments of (1) direction, (2) surface orientation, (3) horizontal/vertical bisection, and (4) height/distance matching all provide converging evidence that perceived gaze (or angular) declination is exaggerated with a gain of about 1.5 relative to actual gaze declination. Although the scaling ambiguity with respect to perceived distance remains intact (perhaps people exaggerate their eye-height, but accurately perceive ground distance), there does not seem to be a scaling ambiguity with regard to perceived angular declination. The errors observed in perceived gaze declination, as shown in Figure 2, imply that perceived distance is indeed compressed (when expressed in perceived eye-height units). The amount of compression predicted by the angular expansion of 1.5 is very close to the frequentlyobserved distance underestimation ratio of 0.7 .

Although observed verbal estimates of egocentric distance are often less distorted than 0.7, this improved performance may be largely due to explicit verbal recalibration. As discussed above, many athletes become distance experts simply by being familiar with specific field dimensions (e.g., the distance of a penalty kick, the distance to first base). It has recently been found that elderly adults are fairly accurate at judging distance on grass (Bian \& Andersen, 2013), and this also may be a cognitive result of life experiences. Golfers (and their caddies) are often particularly expert at estimating distances on grass. But golfers still misperceive their gaze declination (Durgin \& Li, 2011a) and athletes still perform like others when asked to match egocentric distance to pole height (Durgin et al., 2012). These facts suggest that the idealized 0.7 ratio of egocentric distance underestimation may 
frequently be violated in practice due to cognitive corrections based on direct verbal calibration, whereas the underlying perceptual distortion remains.

\section{How can action be effective if perception is wrong? The importance of calibration}

The performance of actions with respect to egocentric distance (such as walking) almost never shows any indication of systematic perceptual error. If perceptual error is both systematic and stable ${ }^{1}$, actions will become calibrated to it. Thus, the angular biases we are discussing, though quite large, are evidently stable and systematic. How can motor calibration overcome this?

Consider the studies of Ooi, $\mathrm{Wu}$ and $\mathrm{He}(2001,2006)$ showing that actions are calibrated to angular declination. Ooi et al. used a dual task to illustrate that perceived distance was controlled by angular declination even in the dark: Participants viewed a glowing object and were asked to walk to where the object was, but also to then hold their hand at the height of the object. When this was done, participants walked too short for the actual position of the ball on the floor. However, their final hand positions were in line with the true direction of initial gaze, as illustrated in Figure 4A by the gray circles. That is, the error in perceived location of each ball seemed to be an error along the line of sight. Ooi et al. have regarded this experiment as a demonstration that perceived angular declination is accurate. But the same outcome is predicted even if angular declination is not accurately perceived. Panel A represents the experimenter's measurement of the situation, but Panel B of Figure 4 illustrates how the situation in Panel A would actually be perceived by the participant, assuming angular expansion. The participant's sense of walked distance has been calibrated to the distortion in their perceived angular declination, so their actions (measured by the experimenter according to Panel A) are consistent with the perceptual situation as experienced by the participant (i.e., Panel B).

Because both the perceived angle of declination and the perceived walked distance are distorted in common, the subjectively perceived height and distance of the ball still falls along the (misperceived) lines of angular declination (Figure 4A). This perceptual situation predicts the same behavior as occurs in actuality (Figure 4B), showing that the experimental data from action measures like these do not discriminate between accurate and inaccurate perception of distance and direction, though they do show the importance of angular variables in the control of action.

Note that when action measures are interpreted as perceptual matching tasks, they can be used to demonstrate the differential scaling of egocentric and frontal ground extents. For example, when pantomime walking (walking obliquely to represent an extent) is used to assess both perceived egocentric distances and perceived exocentric frontal extents, it supports the interpretation that calibration of walking to egocentric perception of distance

\footnotetext{
${ }^{1}$ The popular view that perception is not stable (e.g., Proffitt, 2006) has been extensively critiqued by our lab and others (Durgin et al., 2009; Durgin et al., 2010; Durgin, DeWald, Lechich, Li \& Ontiveros, 2011; Durgin, Klein, Spiegel, Strawser \& Williams, 2012;

Firestone, 2013; Firestone \& Scholl, 2014; Shaffer \& Flint, 2011; Shaffer, McManama, Swank \& Durgin, 2013; Woods, Philbeck \& Danoff, 2009).
} 
(i.e., the under-estimation of their own walked distance) makes people walk too far when trying to walk out a frontal extent ( $\mathrm{Li}$ et al., 2013).

\section{Why should perception be systematically wrong? The sensitivity hypothesis}

The argument so far is that there are systematic biases in the perception of locomotor space and that normal actions are calibrated to this space so the distortions are transparent to action. But what possible reason could there be for having such a distortion? Accurate perception is unnecessary for accurate action, so long as the mapping between perception and action is stable and can be learned. But this does not answer the question of why there is systematic error in perception. A lack of need for accuracy is an insufficient theoretical account of why there is a systematic bias. What has recently been proposed as an explanation is that the bias serves the goals of improving action control by improving action feedback (Durgin \& Li, 2011a).

The precision of action control can be limited by the perceptual sensitivity available. One's actions can be therefore more finely tuned if one's perceptual feedback is more finely coded (see Durgin, 2009). Perceptual feedback can be enhanced optically, for example, by the use of magnification: A watchmaker who uses a magnifying glass to see the small parts he or she is manipulating is more successful in his or her actions despite the rescaling that the magnifying glass accomplishes (Durgin, Hajnal, Li, Tonge \& Stigliani, 2010; Hajnal, Abdul-Malak \& Durgin, 2011). In the present case, angular expansion is not due to an optical shift (which would increase visual resolution), but rather a coding choice that is hypothesized to expand the internal scaling of a crucial angular variable.

As the brain transmits information about angular declination from perceptual to motor systems, it probably has a limited bandwidth channel over which to pass that information reliably. Indeed, bandwidth limitations may be necessary to maintain error correction systems responsible for the stable transmission of perceptual variables. Under such conditions, the limited bandwidth available might cause the system to distribute coding unevenly by favoring the part of the range used most. This is a compression/coding strategy that is known as Huffman coding, and it is also consistent with a Bayesian prediction strategy. The apparent linearity of the distortion in perceived declination suggests a further constraint on the coding choice.

If actions like walking are governed by neural estimates of angular variables like gaze declination (or angular declination), then the neural transmission of this variable between perceptual and motor systems ought to retain maximum differentiation among different declinations. If the neutrally-implemented coding of this variable is adapted so as to maximally differentiate among the values most important for evaluating egocentric ground distance, then the decision to exaggerate differences by a factor of 1.5 may make sense: Over the range from $0-45^{\circ}$, expansion by this factor will improve the effective coding precision available for the control of motor action. Not only is gaze rarely directed lower than about $35^{\circ}$ during locomotion (Marigold \& Patla, 2006), but past $45^{\circ}$, egocentric distances along the ground become frontal to gaze (i.e., when gaze is directed downward). 
Thus, relative to normal straight-ahead gaze, expanded coding of angles by 1.5 has no adverse consequences (whereas expanding by a factor of 3 would be unsuitable). The advantage gained by this coding scheme would be to retain greater coding resolution over a smaller range (smaller than $0-90^{\circ}$ ) in the coding of perceived declination.

\section{Conclusions}

Evidence from the distortion of angular variables helps to corroborate the idea that, relative to perceived eye-height, the perception of egocentric distance is systematically compressed. Because angular variables are inherently encoded on a scale that is non-arbitrary and bounded at both ends (i.e., the linear range between horizontal and vertical), the converging evidence for systematic biases in perceived angular declination means that it is appropriate to speak of the mis-scaling of perceived distance with greater confidence. Note that this angular theory is unrelated to prior descriptions of correlations between perceived extent and visual angles (Kudoh, 2005; Levin \& Haber, 1993), but it provides a new interpretation of the findings of Higashiyama (1996). The main conclusion to be drawn from this review is that there are clearly systematic biases in the human perceptual coding of locomotor space as revealed by multiple methodologies designed to examine perceived angular declination. Because actions are calibrated to perceptual experience, the use of action measures allows one to draw only limited conclusions about perceptual scaling. Perceptual matching tasks strongly support the idea that angular variables relevant to evaluating egocentric distance are coded on an expanded scale. This expanded scaling is sufficient to account for a great deal of historical data suggesting that egocentric ground distance is perceptually underestimated and that the perceptual scaling of both vertical and horizontal frontal extents differ from the scaling of egocentric extents in depth along the ground.

\section{Acknowledgments}

This research was supported by Award Number R15 EY021026 from the National Eye Institute. The content is solely the responsibility of the authors and does not necessarily represent the official views of the National Eye Institute or the National Institutes of Health.

\section{References}

Bian Z, Andersen GJ. Aging and the perception of egocentric distance. Psychology and Aging. 2013; 28:813-825. [PubMed: 23276215]

Chapanis A, Mankin DA. The vertical-horizontal illusion in a visually-rich environment. Perception \& Psychophysics. 1967; 2:249-255.

Da Silva JA. Scales for perceived egocentric distance in a large open field: Comparison of three psychophysical methods. The American Journal of Psychology. 1985; 98:119-144. [PubMed: 4003616]

Durgin FH. When walking makes perception better. Current Directions in Psychological Science. 2009; 18:43-47.

Durgin FH, Akagi M, Gallistel CR, Haiken W. The precision of locomotor odometry in humans. Experimental Brain Research. 2008; 193:429-436. [PubMed: 19030852]

Durgin FH, Baird JA, Greenburg M, Russell R, Shaughnessy K, Waymouth S. Who is being deceived? The experimental demands of wearing a backpack. Psychonomic Bulletin \& Review. 2009; 16:964969. [PubMed: 19815806]

Durgin FH, DeWald D, Lechich S, Li Z, Ontiveros Z. Action and motivation: Measuring perception or strategies? Psychonomic Bulletin \& Review. 2011; 18:1077-1082. [PubMed: 21912998] 
Durgin FH, Hajnal A, Li Z, Tonge N, Stigliani A. Palm boards are not action measures: An alternative to the two-systems theory of geographical slant perception. Acta Psychologica. 2010; 134:182-197. [PubMed: 20176342]

Durgin FH, Klein B, Spiegel A, Strawser CJ, Williams M. The social psychology of perception experiments: Hills, backpacks, glucose and the problem of generalizability. Journal of Experimental Psychology: Human Perception and Performance. 2012; 38:1582-1595. [PubMed: 22428672]

Durgin FH, Leonard-Solis K, Masters O, Schmelz B, Li Z. Expert performance by athletes in the verbal estimation of spatial extents does not alter their perceptual metric of space. i-Perception. 2012; 3(5):357-367. [PubMed: 22833782]

Durgin FH, Li Z. Perceptual scale expansion: An efficient angular coding strategy for locomotor space. Attention, Perception \& Psychophysics. 2011a; 73:1856-1870.

Durgin FH, Li Z. The perception of 2D orientation is categorically biased. Journal of Vision. 2011b; 11(8):13, 1-10. [PubMed: 21784870]

Durgin, FH.; Li, Z. Spatial biases and the haptic experience of surface orientation. In: El Saddik, A., editor. Haptics Rendering and Applications. Intech; 2012. p. 75-94.

Durgin FH, Li Z, Hajnal A. Slant perception in near space is categorically biased: Evidence for a vertical tendency. Attention, Perception \& Psychophysics. 2010; 72:1875-1889.

Durgin FH, Reed C, Tigue C. Step frequency and perceived self-motion. ACM Transactions on Applied Perception, 4(1): Article. 2007; 5:1-23.

Firestone C. How "paternalistic" is spatial perception? Why wearing a heavy backpack doesn't—and couldn't—make hills look steeper. Perspectives on Psychological Science. 2013; 8:455-473.

Firestone C, Scholl BJ. "Top-down" effects where none should be found: The El Greco fallacy in perception research. Psychological Science. 2014; 25:38-46. [PubMed: 24297777]

Foley JM, Ribeiro-Filho NP, Da Silva JA. Visual perception of extent and the geometry of visual space. Vision Research. 2004; 44:147-156. [PubMed: 14637364]

Gilinsky AS. Perceived size and distance in visual space. Psychological Review. 1951; 58:460-482. [PubMed: 14900306]

Hajnal A, Abdul-Malak DT, Durgin FH. The perceptual experience of slope by foot and by finger. Journal of Experimental Psychology, Human Perception and Performance. 2011; 37:709-719. [PubMed: 20731518]

Higashiyama A. Horizontal and vertical distance perception: The discorded-orientation theory. Perception \& Psychophysics. 1996; 58:259-270. [PubMed: 8838168]

Higashiyama A, Ueyama E. The perception of vertical and horizontal distances in outdoor settings. Perception \& Psychophysics. 1988; 44:151-156. [PubMed: 3405741]

Kelly JW, Loomis JM, Beall AC. Judgments of exocentric direction in large-scale space. Perception. 2004; 33:443-454. [PubMed: 15222392]

Kudoh N. Dissociation between visual perception of allocentric distance and visually directed walking of its extent. Perception. 2005; 34:1399-1416. [PubMed: 16355744]

Levin CA, Haber RN. Visual angle as a determinant of perceived interobject distance. Perception \& Psychophysics. 1993; 54:250-259. [PubMed: 8361840]

Li Z, Durgin FH. Downhill slopes look shallower from the edge. Journal of Vision. 2009; 9(11):6, 115. [PubMed: 20053069]

Li Z, Durgin FH. Perceived slant of binocularly viewed large-scale surfaces: A common model from explicit and implicit measures. Journal of Vision. 2010; 10(14):13, 1-16. [PubMed: 21188784]

Li Z, Durgin FH. A comparison of two theories of perceived distance on the ground plane: The angular expansion hypothesis and the intrinsic bias hypothesis. i-Perception. 2012; 3:368-383. [PubMed: 22792434]

Li Z, Phillips J, Durgin FH. The underestimation of egocentric distance: Evidence from frontal matching tasks. Attention, Perception \& Psychophysics. 2011; 73:2205-2217.

Li Z, Sun E, Strawser CJ, Spiegel A, Klein B, Durgin FH. On the anisotropy of perceived ground extents and the interpretation of walked distance as a measure of perception. Journal of Experimental Psychology: Human Perception and Performance. 2013; 39:477-493. [PubMed: 22889186] 
Loomis JM, Da Silva JA, Fujita N, Fukusima SS. Visual space perception and visually directed action. Journal of Experimental Psychology: Human Perception and Performance. 1992; 18:906-921. [PubMed: 1431754]

Loomis JM, Philbeck JW. Is the anisotropy of perceived 3-D shape invariant across scale? Perception \& Psychophysics. 1999; 61:397-402. [PubMed: 10334089]

Loomis, JM.; Philbeck, JW. Measuring spatial perception with spatial updating and action. In: Klatzsky, RL.; MacWhinney, B.; Behrmann, M., editors. Embodiment, Ego-space, and Action. New York: Taylor and Francis; 2008. p. 1-43.

Loomis JM, Philbeck JW, Zahorik P. Dissociation between location and shape in visual space. Journal of Experimental Psychology: Human Perception and Performance. 2002; 28:1202-1212. [PubMed: 12421065]

Marigold DS, Patla AE. Gaze fixation patterns for navigating complex terrain. Neuroscience. 2006; 144:302-313. [PubMed: 17055177]

Messing RM, Durgin FH. Distance perception and the visual horizon in head-mounted displays. ACM: Transactions on Applied Perception. 2005; 2:234-250.

Ooi TL, He ZJ. A distance judgment function based on space perception mechanisms: Revisiting Gilinsky’s (1951) equation. Psychological Review. 2007; 114:441-454. [PubMed: 17500634]

Ooi TL, Wu B, He ZJ. Distance determined by the angular declination below the horizon. Nature. 2001; 414:197-200. [PubMed: 11700556]

Ooi TL, Wu B, He ZJ. Perceptual space in the dark affected by the intrinsic bias of the visual system. Perception. 2006; 35:605-624. [PubMed: 16836053]

Proffitt DR. Embodied perception and the economy of action. Perspectives on psychological science. 2006; 1:110-122.

Purdy J, Gibson EJ. Distance judgment by the method of fractionation. Journal of Experimental Psychology. 1955; 50:374-380. [PubMed: 13271704]

Riemer M, Hölzl R, Kleinböhl D. Interrelations between the perception of time and space in largescale environments. Experimental brain research. 2014:1-9.

Shaffer DM, Flint M. Escalating slant: Increasing physiological potential does not reduce slant overestimates. Psychological Science. 2011; 22:209-211. [PubMed: 21169523]

Shaffer DM, McManama E, Swank C, Durgin FH. Sugar and space? Not the case: Effects of low blood glucose on slant estimation are mediated by beliefs. i-Perception. 2013; 4:147-155. [PubMed: 23799192]

Teghtsoonian R, Teghtsoonian M. Scaling apparent distance in natural outdoor settings. Psychonomic Science. 1970; 21:215-216.

Wallach H, O'Leary A. Slope of regard as a distance cue. Perception \& Psychophysics. 1982; 31:145148. [PubMed: 7079094]

Woods AJ, Philbeck JW, Danoff JV. The various perceptions of distance: An alternative view of how effort affects distance judgments. Journal of Experimental Psychology: Human Perception \& Performance. 2009; 35:1104-1117. [PubMed: 19653752]

Yang TL, Dixon MW, Proffitt DR. Seeing big things: Overestimation of heights is greater for real objects than for objects in pictures. Perception. 1999; 28:445-467. [PubMed: 10664786] 


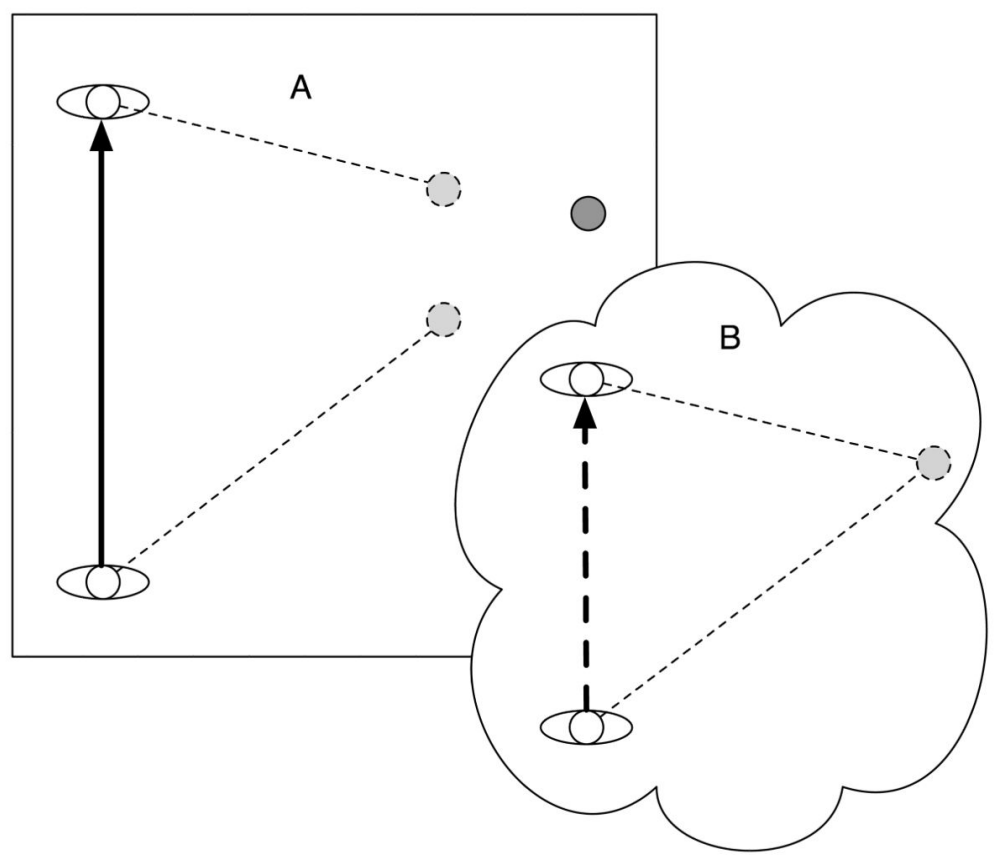

Figure 1.

Panel A depicts the top view of a person who translates along the bold line past a target (dark circle) to his or her right. The dashed lines show the reported direction and distance to the target before and after translation. This apparent failure of triangulation when oblique blind walking is combined with verbally estimated target distance (Loomis \& Philbeck, 2008) is shown in Panel A. But Panel B shows that subjective triangulation was actually successful so long as the perception of walked distance (dashed bold line) is also underestimated, as is to be expected if visual egocentric distance is underperceived. 


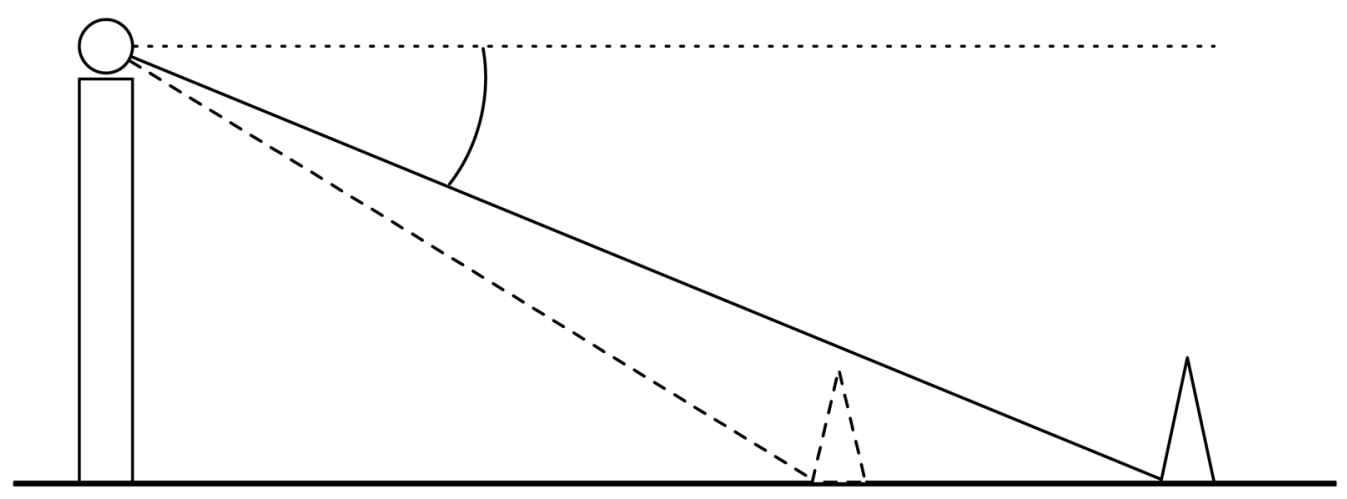

Figure 2.

The angular expansion theory of distance underestimation. Angular (or gaze) declination $(\gamma)$, depicted here as the line from the head to the cone on the ground in side view, is a distance cue. If perceived angular declination (the dashed line) relative to straight ahead (the dotted line) is greater than the actual angular declination, then the perceived egocentric ground distance will be reduced accordingly. 

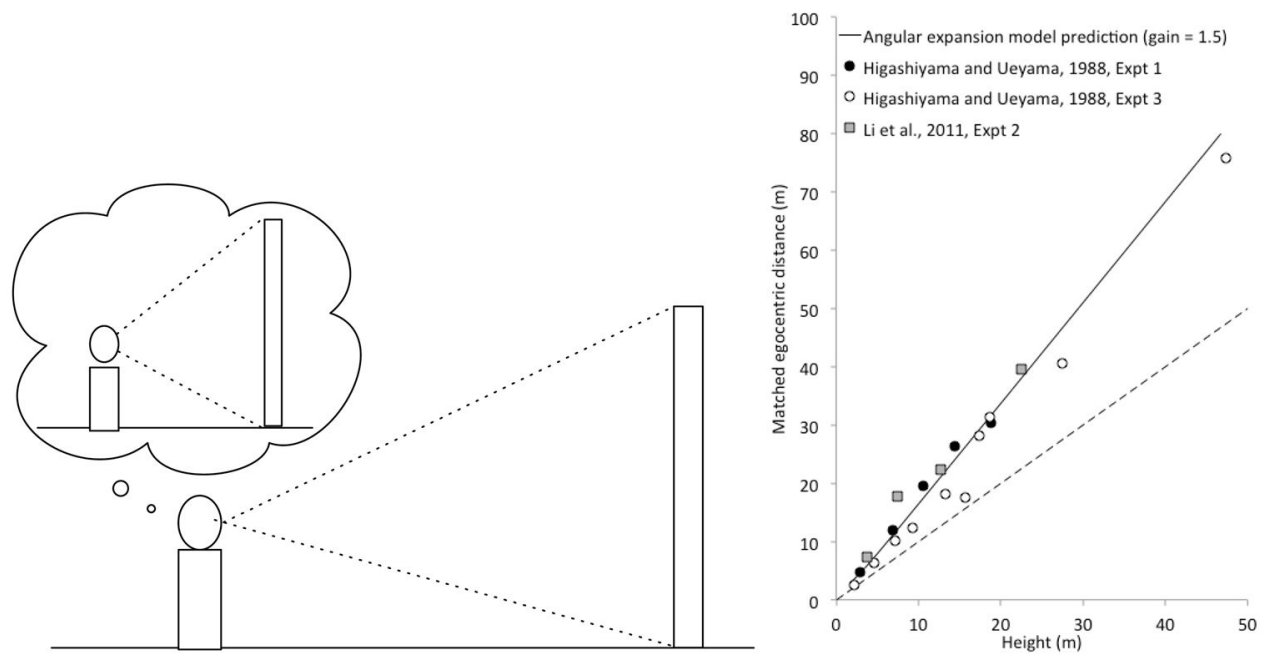

Figure 3.

When asked to match their egocentric distance from a pole to the height of a pole (left), people set themselves much too far away, consistent with the underestimation of egocentric distance. The matched position across multiple experiments (shown at right) can be predicted by a model (the solid line in the graph) that assumes perceived angular deviations from the horizontal are exaggerated with a gain of 1.5. The model has no free parameters, but it can be used to predict both perceived egocentric distance (as shown in Figure 2) and perceived height (i.e. by also expanding the angle above eye-level) by simple trigonometry (Li et al., 2011). 


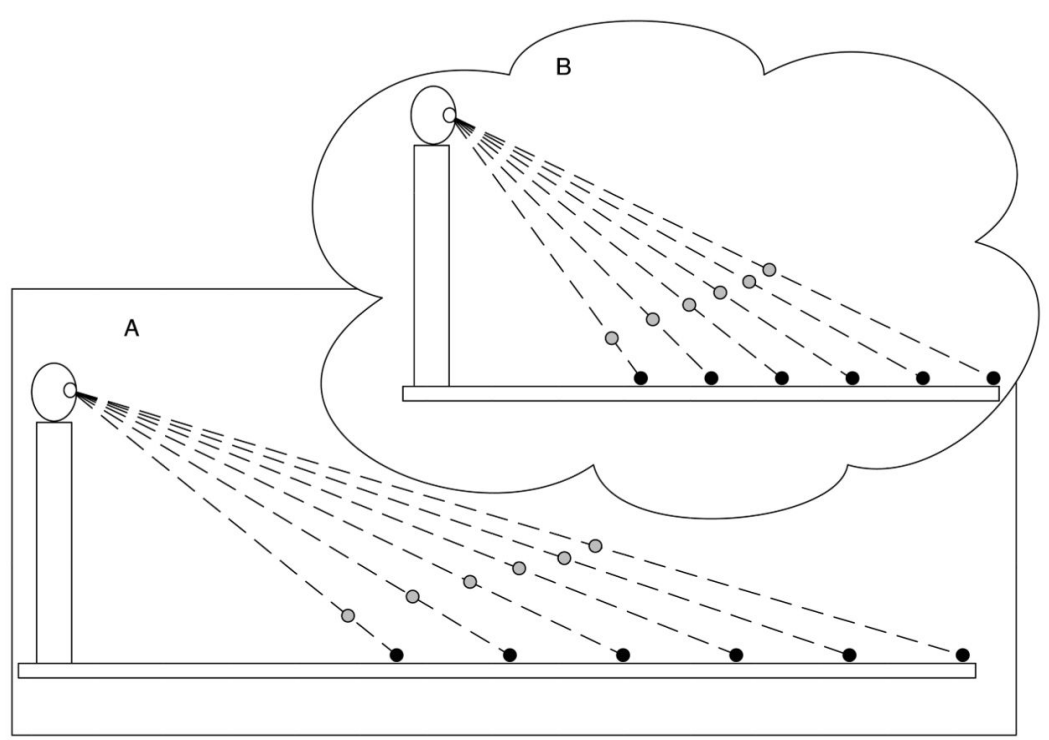

Figure 4.

Panel A depicts that, in the dark, people act as if objects on the floor (black circles) are actually hovering in the air (gray circles). Their actions (walking and then reaching down to the perceived location) are consistent with the correct perception of the direction of their gaze from the starting position (Ooi, Wu \& He, 2001, 2006). But the actions of such a person are also consistent with the concurrent misperception of both direction and distance illustrated in Panel B. The lifelong calibration of perceived walked distance to perceived visual distance is sufficient to make actual action effective (along the line of sight, as in panel A) even though the actor's perception of the situation -- including their amount of self motion -- remains distorted (as in Panel B). 